\title{
MODELAGEM DA RELAÇÃO TEOR/RECUPERAÇÃO DE UMA CÉLULA DE FLOTAÇÃO PNEUMÁTICA
}

\author{
A. Q. N. SILVA* , K. C. FERREIRA, R. GALERY e L. C. M. MONTENEGRO \\ Universidade Federal de Minas Gerais \\ aqns@yahoo.com.br
}

Artigo submetido em novembro/2015 e aceito em julho/2016

DOI: $10.15628 /$ holos.2016.3705

\section{RESUMO}

A flotação viabilizou o beneficiamento de muitos recursos minerais pela possibilidade de concentrar elementos úteis de reservas minerais de baixo teor. A busca por alternativas que simplifiquem os processos e atendam as especificações de mercado deve ser constante não só pela redução dos custos, mas também pela possibilidade de gerar alternativas aos processos que são cada vez mais exigidos. Neste contexto, a célula de flotação pneumática surge com possibilidade de aplicação na concentração de minerais de ferro. Neste estudo, foram realizados testes em escala piloto de uma célula de flotação pneumática com um minério de ferro itabirítico. Através da modelagem da célula de flotação pneumática foi possível avaliar o comportamento da recuperação metálica e teor de quartzo do concentrado para as diferentes condições operacionais testadas. Em nenhum dos testes e variáveis testadas foi possível alcançar a especificação de $\mathrm{SiO} 2$ no concentrado almejada, isto devido ao baixo grau de liberação do minério na granulometria testada

PALAVRAS-CHAVE: flotação pneumática, minério de ferro, flotação

\section{MODELLING THE GRADE/RECOVERY RELATION IN A PNEUMATIC FLOTATION CELL}

\begin{abstract}
The flotation enabled the processing of many mineral resources by the possibility of concentrating elements of poor mineral reserves low grade minerals. The search for alternatives to simplify processes and meet market specifications should be constant not only by reducing costs, but also by the possibility of generating alternatives to processes that are increasingly required. In this context, the pneumatic flotation cell arises with the possibility of applying the concentration of iron minerals.
\end{abstract}

In this work were performed a pilot test scale with an itabirite iron ore in a pneumatic cell. Through modelling the pneumatic cell it was possible evaluate the behavior of the metal recovery and the quartz content in concentrate for various operating conditions. None of the tests and variables tested was possible allowed to achieve the desired quartz content in concentrate, that probably due to the low liberation of the ore in the size tested.

KEYWORDS: Pneumatic flotation cell, iron ore, flotation. 


\section{INTRODUÇÃO}

O método de concentração por flotação tem viabilizado projetos cujos depósitos são formados por minérios de baixo teor. A célula de flotação pneumática surge com possibilidade de aplicação na concentração de minerais de ferro. Poucas são as informações da célula de flotação pneumática operando na concentração de minério de ferro (SILVA, 2015).

As células de flotação pneumática vêm sendo estudadas como uma alternativa de equipamento mais eficiente para a etapa de concentração através de flotação. Tem sua origem na década de 1980 na Alemanha, e suas vantagens têm sido verificadas em campo. Em relação aos outros equipamentos, a célula pneumática apresenta dimensões menores, sendo que os projetos envolvendo este equipamento apresentam estrutura menor. As dimensões menores se devem ao baixo tempo de residência necessário pelo equipamento, apresentam também, uma maior produtividade verificada em campo. Todas essas vantagens apresentadas podem ser explicadas por uma geração de bolhas com diâmetro menor, proporcionando uma maior cinética de coleta e transportando uma maior quantidade de sólidos por volume de ar (OLIVEIRA, 1988).

Os resultados obtidos por LIMA (2013) e ULIANA (2013) demonstram um elevado potencial de concentração do minério de ferro empregando flotação pneumática para a concentração de minério de ferro para a obtenção de pellet feed dentro das especificações do mercado.

Este estudo apresenta os resultados de testes realizados para a flotação em célula pneumática com o objetivo de mostrar o efeito das variáveis operacionais (camada de espuma, vazão de ar e porcentagem de sólidos) nos resultados de recuperação metálica e porcentagem de sílica do concentrado de minério de ferro. O cálculo da recuperação utilizou o modelo de recuperação por flotação verdadeira e arraste mecânico (MONTENEGRO, 2001) e recuperação na zona de coleta e zona de limpeza.

\section{METODOLOGIA}

No estudo, os testes foram realizados em uma célula piloto, o minério utilizado nos testes foi um minério de ferro itabirítico de baixo teor com baixa liberação e a operação foi realizada através da flotação catiônica reversa. A célula de flotação pneumática destaca-se pela simplicidade de operação e pelo intenso contato partícula/bolha promovido pelo sistema de alimentação da polpa, já aerada.

O teste de flotação com o minério de ferro itabirítico foi realizada com as condições apresentadas abaixo. O mesmo, apresentou granulometria $100 \%<150 \mu \mathrm{m}$.

- Amina e amido dosados como coletor de silicatos e depressor de minerais portadores de ferro, respectivamente;

- Dosagem de amina EDAC da Clariant em 110g/t;

- Dosagem de amido em $450 \mathrm{~g} / \mathrm{t}$;

- Flotação em pH 10,5;

- Polpa com $50 \%$ de sólidos na flotação;

- Vazão de ar em $125 \mathrm{~L} / \mathrm{h}$;

- 2 minutos para condicionamento do coletor e 5 minutos para condicionamento do 
depressor.

A célula piloto de flotação pneumática $\left(\right.$ Pneuflot $^{\circledR}$ ) utilizada possui capacidade volumétrica de 11 litros. Este equipamento possui um condicionador e uma bomba de alimentação que realiza a aeração da polpa antes de ser alimentada na célula. A Figura 1 apresenta a imagem do equipamento utilizado e a Figura 2 apresenta o fluxograma do circuito utilizado.

Sete amostragens na alimentação, concentrado e rejeito foram realizadas no teste para análises químicas e posterior cálculo das recuperações.

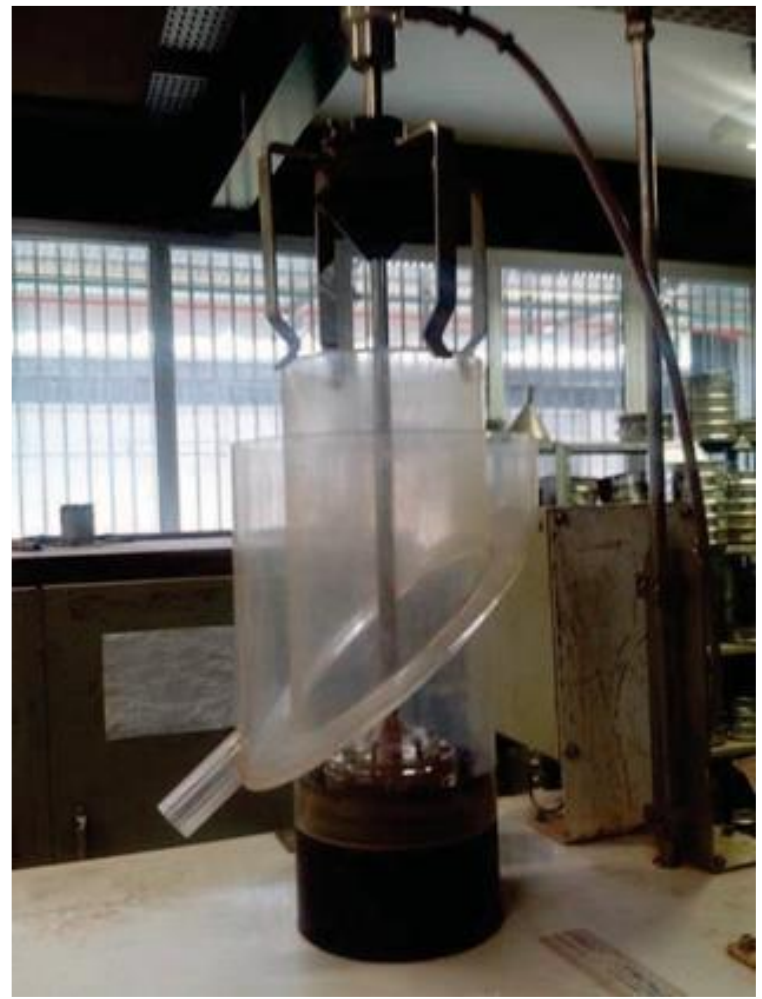

Figura 1. Célula pneumática utilizada no teste piloto.

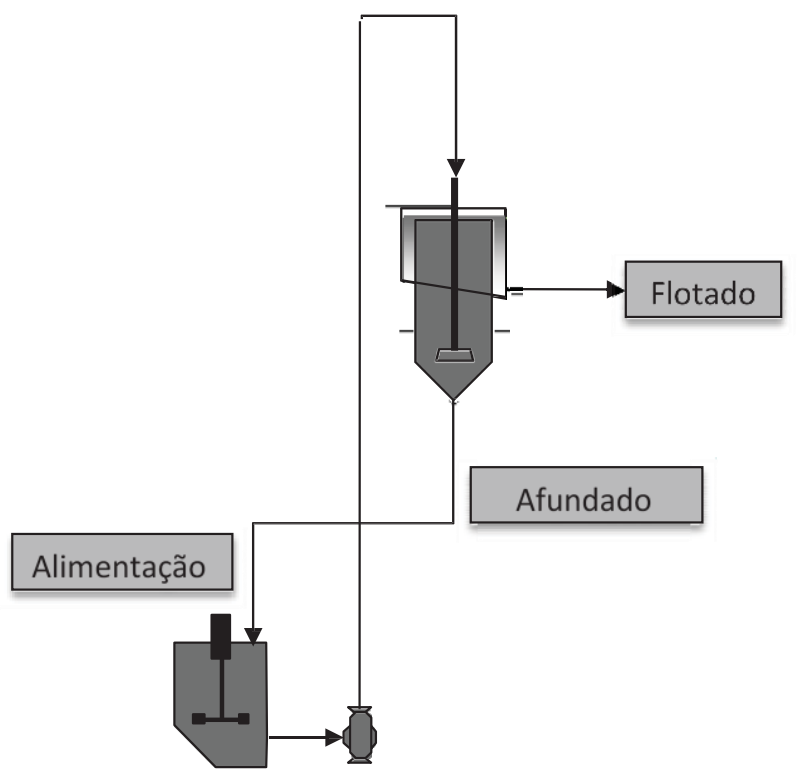

Figura 2. Fluxograma do teste de flotação pneumática utilizado. 
O cálculo da recuperação utilizou o transporte de massa na zona de coleta e zona de espuma por flotação verdadeira e por arraste mecânico desenvolvido por Montenegro (2001) aplicado em uma célula de flotação pneumática (Silva, 2015). A Figura 3 mostra o balanço de massa correspondente e a Equação 01 mostra o cálculo da recuperação que considera a recuperação por flotação verdadeira e por arraste mecânico (Rc e R(ent)c), respectivamente, e a recuperação da camada de espuma por flotação verdadeira e por arraste mecânico ( $R f$ e $R(e n t) f)$, respectivamente.

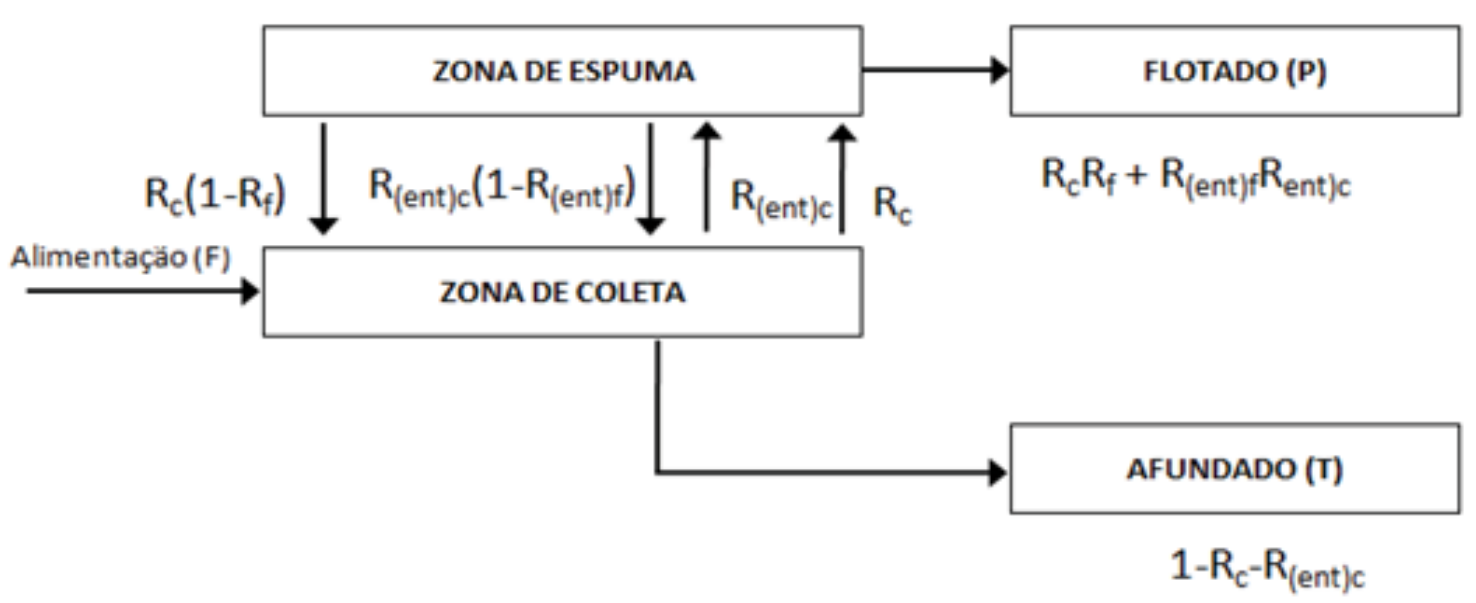

Figura 3. Modelo para cálculo da recuperação mineral em sistema de flotação considerando zona de coleta, zona de limpeza, recuperação por flotação verdadeira e por arraste mecânico na zona de coleta e zona de limpeza (MONTENEGRO 2001).

$$
R=\frac{P}{F}=\frac{R_{c} R_{f}+R_{(e n t) c} R_{(e n t) \mathrm{f}}}{R_{c} R_{f}+R_{(e n t) c} R_{(e n t) \mathrm{f}}+R_{c}-R_{(e n t) c}}
$$

Foi também realizado a análise de liberação do minério de ferro itabirítico. Para tal, utilizouse um sistema de processamento de análise digital de imagens denominado LibMin. O LibMin analisa imagens de elétrons retroespalhados tomadas em microscópio eletrônico de varredura (MEV).

\section{RESULTADOS E DISCUSSÃO}

A Figura 4 apresenta as curvas obtidas da recuperação de $\mathrm{Fe}_{2} \mathrm{O}_{3}(\%)$ versus teor de $\mathrm{SiO}_{2}(\%)$ para diferentes tamanhos de camada de espuma e diferentes tempos de residência para coleta. A maior camada de espuma $(10,0 \mathrm{~cm})$ trabalhou com maior seletividade gerando maior recuperação metálica, entretanto reduziu a sílica para $30 \%$ no concentrado. Já a menor camada de espuma $(1,0 \mathrm{~cm})$ foi capaz de reduzir a sílica para $6,6 \%$ no concentrado. No gráfico, foi construída uma linha "objetivo do quartzo" indicando a especificação adequada da porcentagem de sílica para o concentrado. Para as diferentes camadas de espuma testada, não foi possível chegar a este valor indicando possível problema de liberação do minério testado. 


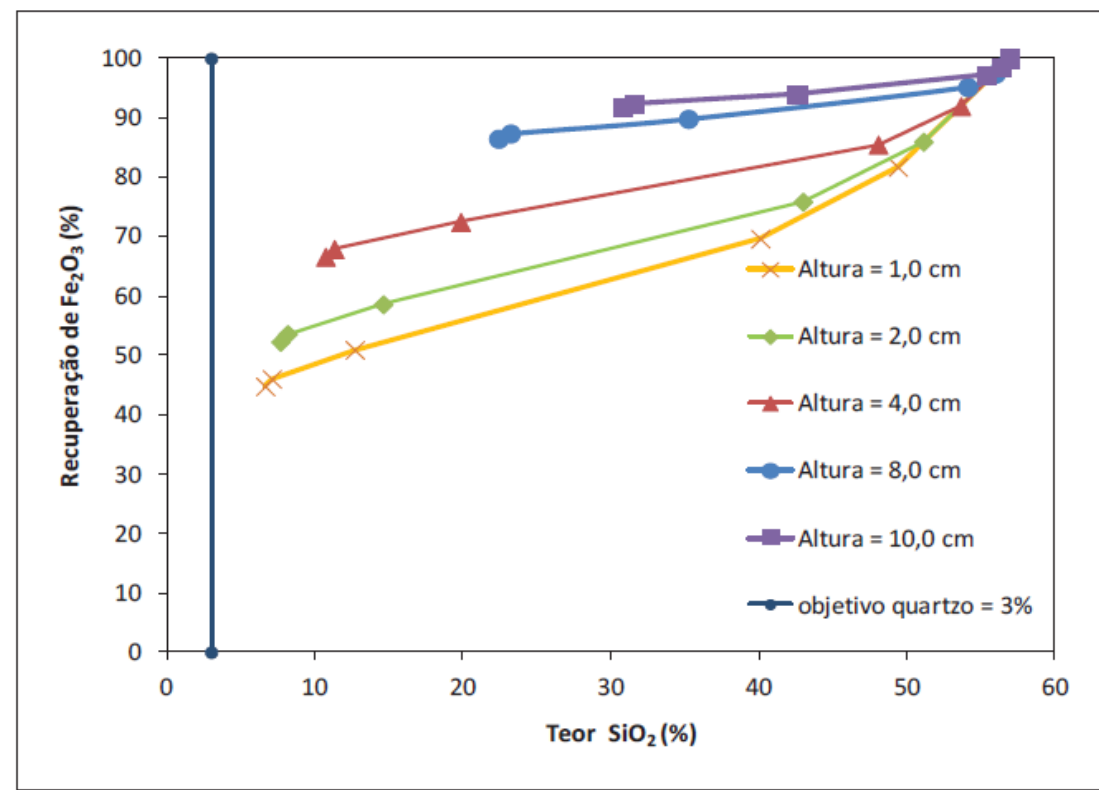

Figura 4. Efeito da camada de espuma sobre a recuperação da hematita e teor de quartzo no concentrado da célula de flotação pneumática piloto alimentada com minério de ferro.

O efeito da variação da porcentagem de sólidos na relação teor versus recuperação é mostrado na Figura 5. Para as diferentes porcentagens de sólido, o resultado final da recuperação metálica e teor de quartzo foi o mesmo. Entretanto, na etapa rougher, que ocorreu no tempo de 3 minutos no equipamento utilizado, as menores porcentagens de sólidos testadas apresentam maior redução da porcentagem de sílica na etapa rougher.

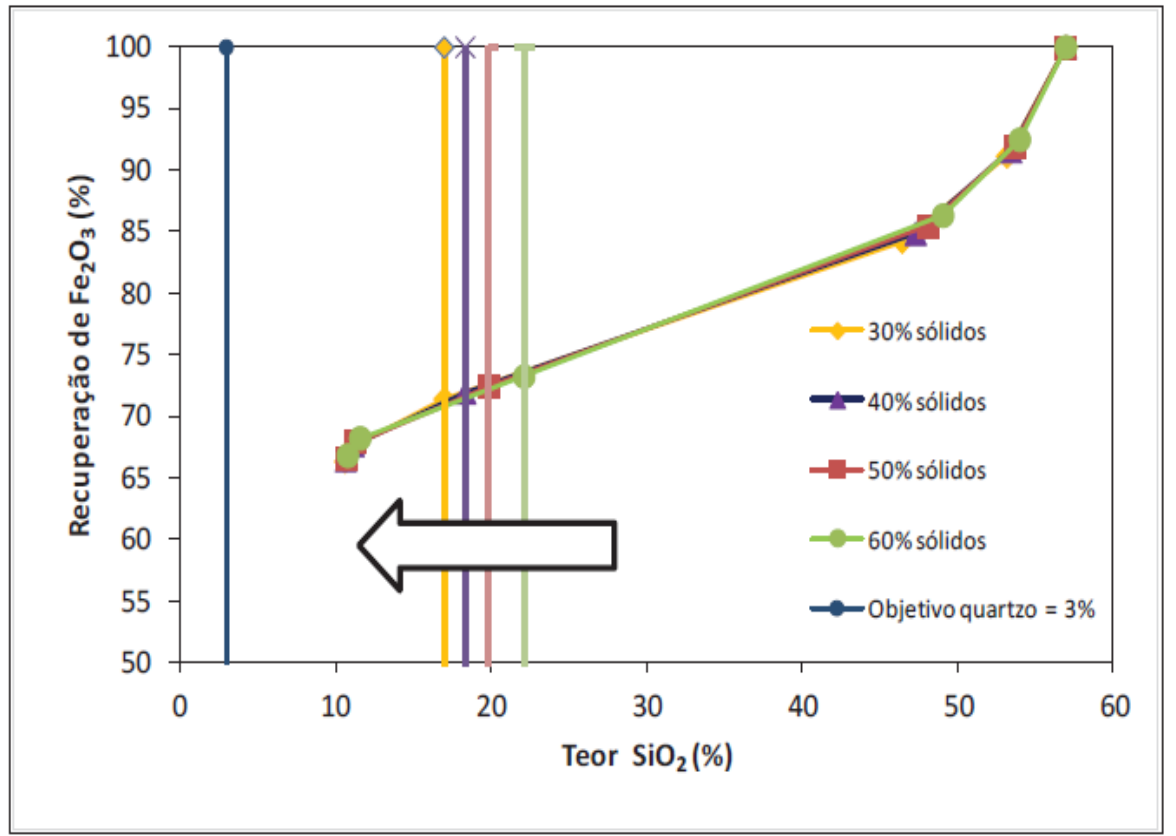

Figura 5. Efeito da porcentagem de sólidos sobre a recuperação da hematita e teor de quartzo no concentrado da célula de flotação pneumática piloto alimentada com minério de ferro.

O efeito da vazão de gás sobre a relação teor recuperação na célula de flotação pneumática é ilustrado na Figura 6. A vazão do gás é uma das variáveis mais importantes no controle do processo de flotação (FINCH e DOBBY, 1990). A recuperação do mineral flotado cresce com o aumento da vazão de ar, e a recuperação do mineral $\mathrm{Fe}_{2} \mathrm{O}_{3}$ decresce. As curvas mostram que, com 
o aumento da vazão, ocorre uma redução do teor de quartzo no afundado. Por outro lado, ocorre uma menor recuperação da hematita no afundado pela redução da seletividade do processo. Com a vazão de arde $34,7 \mathrm{~cm}^{3} / \mathrm{s}$, o teor de sílica obtida no concentrado foi de $10,1 \%$ e recuperação de $67 \%$ no concentrado. A vazão do gás quatro vezes superior ao valor experimental forneceu uma recuperação de $43 \%$ no concentrado e teor de sílica de $6 \%$.

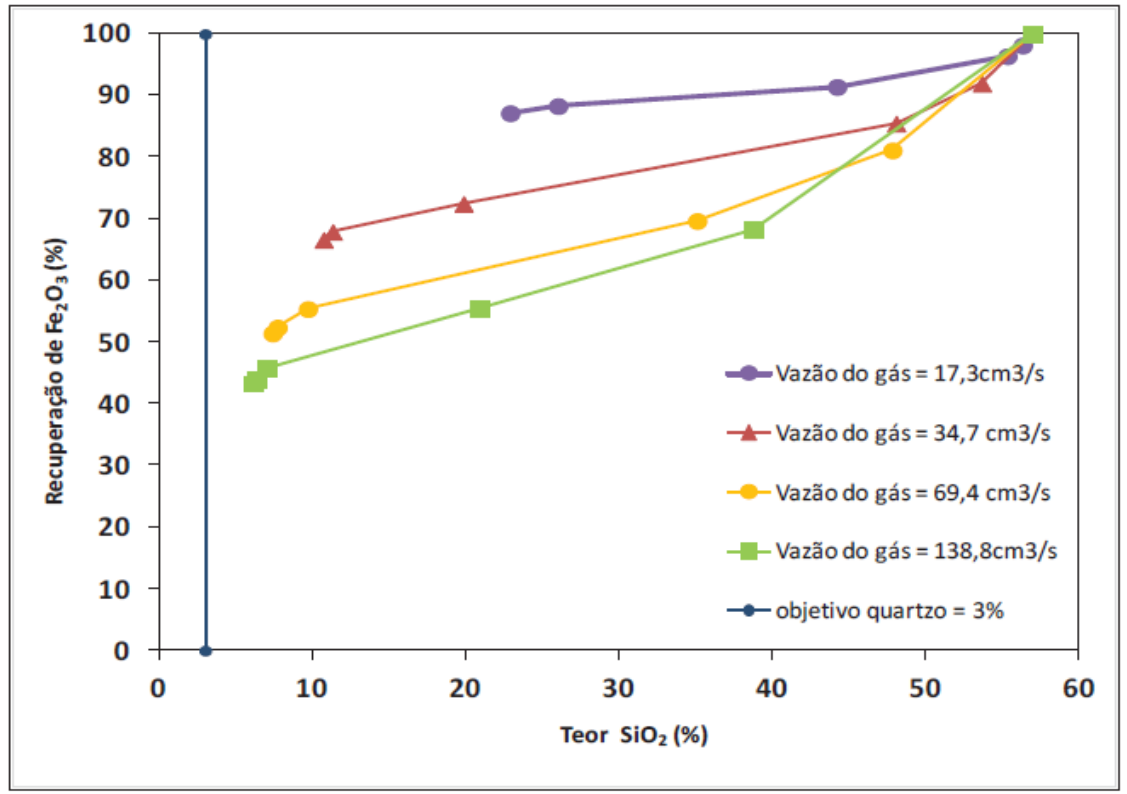

Figura 6. Efeito da vazão do ar sobre a recuperação da hematita e teor de quartzo no concentrado da célula de flotação pneumática piloto alimentada com minério de ferro.

Para os testes realizados, a dificuldade em obter produtos dentro da especificação da sílica se deve a baixa liberação do minério testado. As curvas obtidas dos testes realizados não extrapolaram os resultados para que se chegasse a um valor dentro do objetivo da porcentagem de quartzo no concentrado indicando uma coerência com a característica do minério e condições do teste. O resultado da análise de liberação é mostrado na Figura 7, conforme apresentado por Mazzinghy (2014).

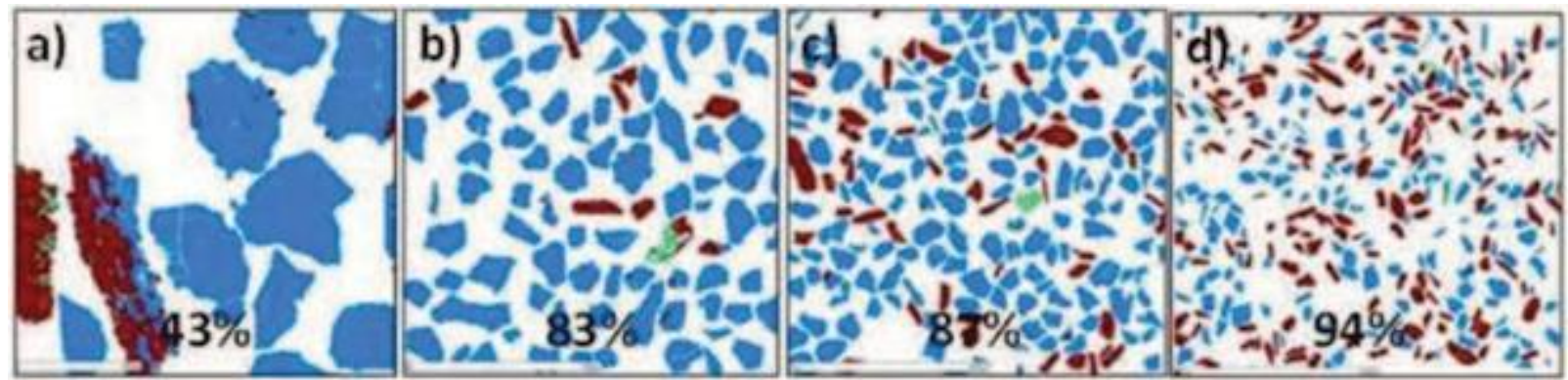

Figura 7. Liberação do quartzo em diferentes faixas de tamanho: a) $+300 \mathrm{~mm}$, b) $-0,100+0,074 \mathrm{~mm}, \mathrm{c})-0,074+$ $0,044 \mathrm{~mm}, \mathrm{~d})-0,044+0,037 \mathrm{~mm}$. Hematita = vermelho, quartzo = azul e outros minerais =verde.

Na Figura 7, a maior liberação (94\%) acontece na faixa de tamanho inferior a $44 \mu \mathrm{m}$. A distribuição granulométrica do minério testado encontra se na Tabela 1 indicando apenas 24,6\% da massa alimentada inferior a $44 \mu \mathrm{m}$ comprometendo a especificação de sílica do concentrado. 
Tabela 1. Granuloquímica da alimentação.

\begin{tabular}{c|c|c|c}
\hline Abertura $(\mu \mathrm{m})$ & $\%$ massa & $\mathrm{Fe}_{2} \mathrm{O}_{3}$ & $\mathrm{SiO}_{2}$ \\
\hline 106 & 34,4 & 20,97 & 78,4 \\
$-106+75$ & 14,9 & 25,2 & 74,53 \\
$-75+53$ & 15,8 & 34,81 & 65,15 \\
$-53+45$ & 10,3 & 54,21 & 45,53 \\
$-45+38$ & 5,3 & 63,81 & 34,32 \\
$<38$ & 19,3 & 78,02 & 20,08 \\
\hline \multirow{2}{*}{ Global Calculada } & 100 & 40,5 & 58,74 \\
\hline
\end{tabular}

\section{CONCLUSÕES}

A modelagem da célula de flotação pneumática ofereceu a possibilidade de avaliar o comportamento da recuperação metálica e teor de quartzo do concentrado para as diferentes condições operacionais testadas e os resultados apresentados são coerentes com a bibliografia, porém em nenhum dos testes se alcançou a especificação necessária de $\mathrm{SiO}_{2}$ no concentrado.

Para o minério com granulometria $<150 \mu \mathrm{m}$, o modelo utilizado foi capaz de limitar os resultados indicando uma coerência com a informação de que a liberação deste minério ocorre na faixa granulométrica de $44 \mu \mathrm{m}$ e, portanto, a massa testada necessitaria de uma remoagem para que o concentrado atingisse as especificações de $\mathrm{SiO}_{2}$.

\section{REFERÊNCIAS BIBLIOGRÁFICAS}

1. FINCH, J.A., DOBBY, G.S., Column Flotation. 1ed. Ontario: Pergamon Press, 1990.

2. LIMA, N.P. Avaliação da flotação pneumática para minério de ferro; In: 140 SIMPÓSIO BRASILEIRO DE MINÉRIO DE FERRO, 09, 2013, Belo Horizonte. Anais, ABM, 2013, p.581-588.

3. MAZZINGHY, D.B., TURRER, H.D.G., RUSSO, J.F.C., TAVARES, L.M. Influence of the mineralogical structure in grinding specific energy consumption of itabirite iron ores, International Comminution Symposium, Cape Town, n.9, 2014.

4. MONTENEGRO, L.C.M., Efeito das Condições Operacionais Sobre a Relação Teor- Recuperação na Flotação de Minério de Ferro. [Tese de Doutorado]. Escola de Engenharia da UFMG, Belo Horizonte, 2001.

5. OLIVEIRA, R.N. Desenvolvimento de um equipamento não-convencional em beneficiamento mineral: a célula serrana de flotação pneumática [dissertação de mestrado]. São Paulo: Escola Politécnica da Universidade de São Paulo; 1988.

6. SILVA, A.Q.N., Modelagem da relação teor-recuperação da célula de flotação pneumática. [Dissertação de Mestrado]. Escola de Engenharia da UFMG, Belo Horizonte, 2015.

7. ULIANA, A.; JÚNIOR, L.C.; ARAÚJO, V. Aplicação de células pneumática de flotação no processo de concentração de minério de ferro da Samarco Mineração S.A.; 14오 SIMPÓSIO BRASILEIRO DE MINÉRIO DE FERRO, 09, 2013, Belo Horizonte. Anais, ABM, 2013. p.635-642. 